\title{
LOS MORISCOS, SOCIEDAD MARGINADA EN EL TEATRO ESPAÑOL DEL SIGLO XVII
}

\author{
Miguel Ángel Auladell*
}

Salvando el atrevimiento, por mi falta de especialización, de incluir este trabajo en un Coloquio específicamente dedicado a "La Voz de Mudéjares y Moriscos", quiero, en primer lugar, agradecer la invitación a participar en él, que me hizo la Prof. ${ }^{a}$ M. $^{a}$ Jesús Rubiera, para, enseguida, advertir que mi intervención se sale del estricto ámbito de estudio que ocupa a los participantes en estas reuniones y que aborda un aspecto tangencial, pero que creo enriquece la visión general del problema.

Me voy a centrar en una serie de materiales, algunos de ellos todavía inéditos, que nos remiten a la presencia, alusión o conexión de algún tipo del elemento converso en la comedia barroca española.

Es sabida la riqueza que el género dramático alcanza en la España secentista y es por la gran cantidad de obras por lo que asistimos en ellas a un verdadero noticiario, a un diario que nos aproxima a la vida de los habitantes de la Península en aquel momento histórico. Contamos con tal número de piezas que, sin duda, podemos llegar a configurar una sociología de la comedia barroca ${ }^{1}$, repasando los diferentes estamentos, los oficios, los diversos tipos de villanos o campesinos, etc., viendo cuál es su posición, su "actuación" en la comedia. No obstante, debemos avisar inmediatamente que hemos de tener en cuenta la adscripción de todos esos roles a los "papeles" que, por su rendimiento dramático, son configurados por los poetas (creadores de las piezas teatrales).

Concretamente, sorprende la escasa atención del teatro al elemento converso, pese a que son los temas del honor, de la honra ${ }^{2}$, de la opinión, de la

* Universidad de Alicante.

1. Vid. J.M ${ }^{a}$. Díez-BORQue, Sociología de la comedia española del siglo XVII, Madrid, Cátedra, 1976, y Sociedad y teatro en la España de Lope de Vega, Barcelona, Antoni Bosch, 1978.

2. Son muy conocidos los versos del Arte nuevo de hacer comedias en este tiempo, de Lope de Vega, que dicen: "Los casos de la honra son mejores, / porque mueven con fuerza a toda gente". 
limpieza de sangre, los que generan mayor cantidad de argumentos representables. Tal vez, la marginación social que en la realidad sufrieron los cristianos nuevos sea la razón fundamental para que también sean marginados en la escena, como muestra - una vez más- de que ésta fue, en mayor o menor medida, reflejo del momento. Por otra parte, ningún dramaturgo estaría dispuesto a complicarse demasiado la vida tratando asuntos escabrosos susceptibles de ser entendidos por el Santo Oficio y más cuando el cultivo del arte de Talía no proporcionaba precisamente un prestigio artístico, sino más bien unos sabrosos ingresos que otros géneros no ofrecían. Como apunta José $\mathrm{M}^{\mathrm{a}}$. Díez-Borque: "La comedia, con sus posibilidades de romper los márgenes cronológicos de la actualidad, puede presentar moros y judíos -a pesar de su expulsión- desde criterios valorativos del XVII y no del momento en que sitúa cronológicamente la acción, pero es harto revelador que no presente, prácticamente nunca, la conflictiva figura del converso que tampoco aparece en la restante literatura de la época" ${ }^{\prime 3}$.

La presencia de moros y judíos como personajes de la comedia atiende a las necesidades de carácter dramatúrgico. El autor de la pieza selecciona diversos matices que le sirven de tipificación. En general, se valora negativamente la figura del judío, se le trata de traidor y de usurero y dentro del abundante rosario de referencias antisemitas que inundan la literatura del siglo XVII, se hacen sardónicas alusiones a su peculiar nariz, por ejemplo en Amar sin saber a quién, de Lope de Vega, leemos el siguiente diálogo:

\begin{tabular}{|c|c|}
\hline Rosales. & ra tiene de hombre honrado. \\
\hline Limón. & ¿En qué lo ha visto? \\
\hline Rosales. & $\begin{array}{l}\text { En que tiene } \\
\text { la nariz en su lugar. }\end{array}$ \\
\hline Sancho. & $\begin{array}{l}\text { Tan larga pudiera ser } \\
\text { que adivinaran por ella } \\
\text { de qué tribu descendía. } \\
(\mathrm{I}, \mathrm{p} .445)^{4} \text {. }\end{array}$ \\
\hline
\end{tabular}

Se emplean términos de gran carga semántica como 'cansado', 'muerto', 'viejo', 'cansino', 'traído', 'marrano', 'desasosegado', 'tornadizo', todos ellos aplicados indistintamente a judíos como a musulmanes. Afirma DíezBorque que: "La consideración despectiva del moro o la inferioridad de su apellido aparecen, esporádicamente, en la comedia, que prefiere utilizar elementos más burdos y populares, como el problema de comer tocino, equivalente al lugar común de la nariz para los judíos hasta llegar a la burla abierta" ${ }^{\prime \prime}$, como en La dama boba, también de Lope:

3. J.Ma. DíEZ-BORQue, Sociología de la comedia..., p. 232.

4. Ibídem, p. 236.

5. lbídem, pp. 237-38. 
Fabio. Que derribe luego a Meca, a donde cuelga en cecina, un pernil de su profeta. (III, p. 537) ${ }^{6}$.

Hay también un tono despectivo al tratar del morisco como vendedor ambulante. En la primera obra que hemos citado del Fénix, el gracioso Limón dice:
Destos que traen arquilla con sus ciertos badulaques, mas morisco en los alfaques que de Argel los ve la orilla. $(\mathrm{I}, \text { p. } 446)^{7}$.

Por otra parte, son múltiples las simples alusiones. En Peribáñez y el Comendador de Ocaña -además de la conocida referencia a los "hidalgos cansados"8-, se explicita que la compañía que sigue al protagonista se va a hacer la guerra al enemigo morisco y se incluye, al lado de los tópicos característicos de la comedia lopesca, alguna referencia curiosa como la que apunta Alonso Zamora Vicente en su edición de la obra9"
Blas.
$Y$ vos, señora Costanza, ¿no dais por tantos requiebros
Costanza. Blas, esa cinta de perro, alguna prenda a un soldado? aunque tú vas donde hay tantos,
Blas. que las podrás hacer dellos. las hagan de mi pellejo, si no dejare matados cuantos me fueren huyendo!
Inés. ¿No pides favor, Belardo?
Belardo. Inés, por soldado viejo, ya que no por nuevo amante, de tus manos le merezco. ¡Plega a Dios que los moriscos

6. Ibidem, p. 238.

7. Ibídem.

8. Vid. para documentarse acerca del valor antijudaico de 'cansado': Joseph H. SiLverman, "Some Aspects of Literature and Life in the Golden Age of Spain», en: Estudios de Literatura Española ofrecidos a Marcos A. Morinigo, Madrid, Insula, 1971, p. 151 y ss. También del mismo autor: "Los "hidalgos cansados" de Lope de Vega», en A.D. Kossoff y J. AMOr y VÁQUEZ (eds.), Homenaje a William L. Fichter. Estudios sobre el Teatro Antiono Hispánico y otros ensayos, Madrid, Castalia, 1971, pp. 693-711.

9. En los dos últimos versos reproducidos, "Lope alude [...] a sus propios romances moriscos, que disfrutaron de general aceptación" (en LOPE DE VEGA, Peribáñez y el Comendador de Ocaña, ed. A. Zamora Vicente, Madrid, Espasa-Calpe, 1987, p. 174). 
Inés. Tomad aqueste chapín.

Belardo. No, señora, deteneldo; que favor de chapinazo, desde tan alto, no es bueno.

Inés. Traedme un moro, Belardo.

Belardo. Días ha que ando tras ellos.

Mas, si no viniere en prosa, desde aquí le ofrezco en verso.

En Fuente Ovejuna hay una canción que se entona hacia el final de la primera jornada y en la que aparece la palabra 'moriscos' -si seguimos la edición que de la obra han hecho García de la Santa, García Pavón, Henríquez Ureña y el propio Joaquín de Entrambasaguas ${ }^{10}$-:

Sea bien venido
el Comendadore
de rendir las tierras
y matar los hombres.
¡Vivan los Guzmanes!
iVivan los Girones!
Si en las pazes blando,
dulce en las razones.
Venciendo moriscos,
fuerte como un roble,
de Ciudad Reale
viene vencedore;
que a Fuente Ovejuna
trae los sus pendones.
¡Viva muchos años,
viva Fernán Gómez!
(I, vv. 529-544) ${ }^{11}$.

En una de sus comedias tempranas, Lope también nos introduce en acciones recorridas por musulmanes; nos referimos a Los hechos de Garcilaso de la Vega y Moro Tarfe ${ }^{12}$. Son gran número los personajes caracterizados de 'moros' en la pieza y, al igual que en las famosas cervantinas, hay cautivos cristianos. Esta obra la cita Othón Arróniz ${ }^{13}$ como ejemplo de comedia con

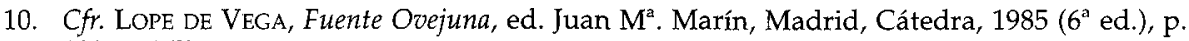
108, n. 167.

11. Ibídem, pp. 108-109.

12. Recogida en Lope Félix de Vega Carpio, Obras escogidas, ed. Federico Carlos Sáinz de Robles, Madrid, Aguilar, 1946-55, t. III, pp. 1204-1223.

13. Othón ARrónIz, La influencia italiana en el nacimiento de la comedia española, Madrid, Gredos, 1969, p. 261. 
algún tipo de efectismo: "indica [Lope] que salga a caballo la reina y dé vuelta al teatro".

En definitiva, la comedia representa los valores de la casta dominante y margina la figura del cristiano nuevo, que no forma parte del esquema basado en tres binomios principales: galán-dama, padre-hijo, criado-criada.

Si lo descrito hasta ahora puede erigirse en regla, contamos con algunas excepciones que pasamos a referir a continuación. Puesto que la presencia del elemento converso en la comedia sirve, ante todo, como motivo de risa, burla y escarnio, debemos deslindar, en primer lugar, aquellas obras "serias", generalmente de carácter histórico, que recogen personajes de ascendiente musulmán, al tratar su argumento de episodios que se desarrollan en tierras ajenas a la Península o en ésta antes de la conquista de Granada. Debemos deslindar de otras, calificadas genéricamente de burlescas ${ }^{14}$, que aportan muestras tanto a los géneros mayores como a los menores. Es precisamente en el teatro breve, en donde contamos con piezas de carácter más desinhibido al tratar estos temas. Las loas, los bailes, las mojigangas y los entremeses constituían un corpus dramático que formaba parte del conjunto del espectáculo de la 'representación' y servían para acompañar la comedia, centro del principal interés. Por ello, los autores podían permitirse mayores libertades en dichas creaciones y es un hecho que las mismas eludían con mayor facilidad el rigor censurante.

El mundo de las fiestas, las mascaradas, los carnavales y todo aquello relacionado con la diversión era susceptible de recoger esa sociedad marginada en el espectáculo teatral. Ya desde la Edad Media y no sólo en la Península, contamos con manifestaciones parateatrales que, incluso como la siguiente que describimos de manera detallada por su interés, se conocía como la 'morisca':

"Los días festivos, la mocedad irrumpía en las plazas ciudadanas y en las de los puertos mediterráneos. Entre los bailarines figuraba un personaje popular, el «Mattacino» (Matachín) ${ }^{15}$. Este, con la faz embadurnada de hollín y tocado con un turbante dorado, llevaba puesto un coselete, amén de cascabeles en torno de ambos tobillos, e iba armado de escudo y espada de madera. Al ritmo de tambores y pífanos, únicos instrumentos usados a la sazón, este Moro, brillante adversario desde hacía varios siglos, danzaba al estilo oriental, y pronto se veía rodeado de sus enemigos parejamente armados. Aquel simulacro de combate concluía invariablemente con la muerte del Matachín. Pero de evocación guerrera, la 'morisca' no tardó en convertirse en diversión: a los

14. Vid. Loly Holgueras PeChaRRomán, «La comedia burlesca: estado actual de la investigación», en J. Huerta Calvo; Harm den Boer y Fermín Sterra Martínez (eds.), Diálogos hispánicos de Amsterdam 8/2. El teatro español a fines del siglo XVII. Historia, cultura y teatro en la España de Carlos II, Amsterdam, Atlanta, 1989, t. II, pp. 467-480.

15. Cfr. el Entremés del Matachín, en Verdores del Parnaso, ed. Rafael Benítez Claros, Madrid, CSIC, 1969, pp. 151-158. 
combatientes se juntaron los cantantes y una mujer cuyo papel corría a cargo de un hombre. Tambores y pífanos continuaban ritmando las evoluciones complicadas, las estocadas de rigor, los gestos de desafío y el tradicional salto sobre las espadas. Tras la batalla danzada venía por último la 'rosa' tan impacientemente esperada, escena final de la pantomima en la que los bailarines, en grupo cerrado, lanzaban al aire al Matachín y sus cascabeles. Poco después, la 'morisca' derivó hacia las representaciones sacras. La 'morisca', como representación sacra, iba emancipándose y acabó por evolucionar hacia una forma lujosa plena de fantasía. A fuerza de enriquecerla con colores, tejidos de oro y plata y con la mímica, así como de evocar la antigüedad, ya no se sabía concretamente de qué se trataba. [En definitiva, la 'morisca' supuso una etapa hacia el ballet, permitiendo] cierta estimable libertad a los coreógrafos de la época, [como ocurrió con] el 'brando', mencionado por Castiglione en 1528 en El Cortesano"16.

Entre las piezas de teatro breve del Siglo de Oro contamos con algunas que reproducen de manera mimética los tics de las comedias, como por ejemplo en el Entremés de los poetas locos, de Villaviciosa ${ }^{17}$, en que se muestra la hostilidad recurrente:

Gracioso. Al arma, guerra, guerra

mueran los Moros, viva nuestra tierra.

Es muy significativa la siguiente intervención del Comisario:

¿Qué novedad es ésta?

En el mismo tono machacón, más adelante es una mujer la que dice:

Levanta perro, y vete a Berbería.

Pero debemos subrayar una creación bastante pintoresca como es la recogida en la Quinta Parte de las Comedias de diferentes autores (Barcelona, 1616): el Baile de los moriscos ${ }^{18}$. En la pieza intervienen músicos "en hábito de moriscos", "cuatro con ellos que bailan" y el morisco Maimón. Es de muy corta extensión; el número de versos no llega al centenar. El comienzo es bastante gracioso, aunque -claro está- se juega con el estribillo fácil que combina diversos sonidos característicos de la fonética árabe. Los parlamentos se llevan a cabo por tres personajes: Maimón y dos músicos. Se alude a la expulsión ordenada por Felipe III, citando explícitamente a los moriscos que vivían en el Reino de Valencia, y al posible paradero en Francia e Inglaterra. Se incluye un léxico sazonado de arabismos como 'tarazanas' (del ar. ad-dar as-si$n a^{\prime} a$, la casa de fabricación, el taller; arsenal de embarcaciones). Aparecen

16. F. REYNA, Historia del ballet, Barcelona, Daimon, 1985, pp, 15-19.

17. Vid. en Vergel de entremeses, ed. Jesús Cañedo Fernández, Madrid, CSIC, 1970, pp. 97-106.

18. Vid. en Francisco GARCía PAVÓN, Teatro menor del siglo XVII (Antología), Madrid, Taurus, 1964, pp. 190-193. En septiembre de 1994, Adrien Roig presentó una comunicación muy interesante, «Le 'Baile des Morisques'», dentro del VI Simposium International d'Etudes Morisques, celebrado en Zaghouan (Túnez). 
nombrados los buñuelos, diciéndose que "hacer boñuelox no toca / a gente crextiana vieja", puesto que son precisamente alimento para la noche del 27 de ramadán ${ }^{19}$. El centro de la trama está en convencer a Maimón para que cante con los músicos y anime el viaje por mar. Es imagen destacable la que muestra el morisco al hacer equivaler el vino a la tierra perdida como producto de la misma; termina Maimón su parlamento más extenso:

$$
\begin{aligned}
& \text { Ya para mí se acabó } \\
& \text { el veno de lax tabernax } \\
& \text { e por exo traemox loto, } \\
& \text { y exta ex toda me trexteza. }
\end{aligned}
$$

La asistencia a una conferencia del Prof. Bartolomé Bennassar me dio noticia de los materiales de los que paso a ocuparme enseguida y que merecen una edición y su análisis pormenorizado. Dentro de un ciclo acerca de la Inquisición, Bennassar hizo referencia a una serie de obras teatrales que con el mismo, motivo argumental se escribieron hacia la mitad del seiscientos. Como es de sobra conocido, el abundante archivo inquisitorial proporciona la mayor parte de noticias que actualmente tenemos sobre los moriscos, puesto que -en palabras de Míkel de Epalza- su "presunta disidencia religiosa" hizo que el Santo Oficio les investigara aspectos de su vida "económicos, (propiedad, producción, fiscalidad...), militares, religiosos, culturales y sociales en general" 20 . El caso es que también encontramos ahí noticia de los renegados: aquéllos que abandonan su fe cristiana para añadirse a las filas del Islam. Pues bien, existen seis manuscritos en la Biblioteca Nacional de Madrid $(17014,16808,17192,15325,17447,17331)$, que a excepción del último, permanecen inéditos y recogen distintas versiones, adaptaciones y hasta algún plagio de la pieza que lleva por título La renegada de Valladolid ${ }^{21}$. El caso es que la obra aparece nombrada en la edición que Manuela Sánchez Regueira hizo de las Comedias de Antonio de Solís 22 ; dice que el dramaturgo la compuso en colaboración con otros dos, Diego de Silva y Francisco A. de Montesser. Y contamos con la publicación del texto que, como decía, contiene el Ms. 17331; se encuentra en el tomo XLV de la Biblioteca de Autores Españoles (B.A.E.), que preparó D. Ramón de Mesonero Romanos con el tí-

19. Vid. Fernando DE LA GRANJA, «Fiestas cristianas en Al-Andalus (materiales para su estudio)», Al-Andalus, XXXV, 1, 1970, p. 122.

20. Míkel de Epalza, Los moriscos antes y después de la expulsión, Madrid, Mapfre, 1992, p. 19.

21. Tras leer esta comunicación el día 31 de marzo de 1995 en el Coloquio Internacional "La voz de mudéjares y moriscos", recibí una carta -con fecha 13 de dicho mes- de Frédéric Serralta, de quien el Prof. Bennassar me había advertido que conocía bien el tema. Efectivamente, Serralta me adjuntaba su memoria de licenciatura, que se publicó con el título de La renegada de Valladolid. Trayectoria dramática de un tema popular (Toulouse, Institut d'Etudes Hispaniques Hispano-Americaines et Luso-Bresiliennes, Université de Toulouse, 1970).

22. Madrid, CSIC, 1984 , p. 1. 
tulo de Dramáticos contemporáneos de Lope de $V e g a^{23}$ y aparece firmada por Luis de Belmonte Bermúdez.

Antes de tratar este corpus, quiero mencionar la existencia de una pintoresca mojiganga que trata el mismo asunto que refieren las comedias manuscritas. Lleva por título Mojiganga cantada y representada de la Renegada de Valladolid"24. El origen de la palabra mojiganga, "según Diego Clemencín, debe ser moxiganga o boxiganga, aplicada a fiestas o bromas que hacían algunas personas disfrazadas. [...] El entremés, el baile, la jácara y la mojiganga propenden a parecerse demasiado y hasta confundirse" 25 . Hay aquí una docena de interlocutores y más de trescientos versos. Cabe mencionar la probable referencia a La niña de Gómez Arias, comedia del autor de El diablo cojuelo, Luis Vélez de Guevara, y que también fue título más tarde de una de Calderón:

Renegada cantando. Señor Gómez Arias, duelete de $\mathrm{mi}$ que soy niña, y sola nunca en tal me vi ${ }^{26}$

Más explícitas son las referencias a una novela ejemplar de Cervantes y a diversas comedias calderonianas:

Capitán.
Hermano, ya sabe que el
hombre pobre todo es trazas,
si es zeloso Estremeño,
yo el marido de su Hermana,
donde ay Valor ay Honor,
antes que todo es mi Dama,
$\mathrm{y}$ ansi con quien Vengo vengo,...27.

El asunto que van a tratar casi unánimemente todas las piezas recogidas en los manuscritos bajo el título de La renegada de Valladolid ${ }^{28}$ se puede resumir de la forma siguiente: D. ${ }^{a}$ Agueda -nombre histórico de la protagonista-, o D. ${ }^{a}$ Isabel -el otro nombre con el que aparece- es una bella y principal dama de la ciudad del Pisuerga que, esperando su padre que profese para religiosa en un convento de monjas, huye, enamorada de un capitán, a Bujía (Argelia), estableciendo relación allí, después de conquistar los moros la ciudad, con el galán musulmán de turno, renegando de su fe cristiana, y

23. Madrid, Atlas, 1951, t. II, pp. 347-366.

24. En Verdores del Parnaso..., pp. 133-149.

25. F. García Pavón, op. cit., pp. 18-19.

26. Verdores del Parnaso..., p. 140.

27. Ibidem, p. 141.

28. F. Serralta recoge algunas muestras más de la trayectoria dramática del tema (vid. n. 32 y n. 34). 
convirtiéndose al Islam; cuando más tarde cae cautivo su hermano sacerdote y llegan a tierras argelinas otros conocidos de la protagonista, la dama vuelve a cambiar de religión y se escapa con ellos de vuelta hacia la Península, no sin antes recalar en Roma para hacer penitencia.

El cotejo de los diferentes manuscritos nos permite apreciar directamente lo que era una habitual práctica de la época entre los poetas. A partir de un resumen -facilitado la mayor parte de las ocasiones por quien hacía el encargo de la comedia-, varios dramaturgos se reparten cada una de las jornadas $y$, siguiendo unos patrones de escuela, elaboran diversas versiones y adaptaciones o crean de manera original la correspondiente obra teatral. Vamos a verlo caso por caso:

$1^{\circ}$.- El Ms. 17.192 contiene la representación completa a la que un espectador de la época podría haber asistido. Así pues, el interés de este manuscrito, al menos desde el punto de vista de la Historia del Teatro, es grande.

El título de la pieza mayor es Comedia Burlesca de la renegada de Valladolid, escrita por tres ingenios: Francisco Monteser (autor de la $1^{\text {a }}$ Jornada), Antonio de Solís ( $2^{\mathrm{a}}$ Jornada), y Diego de Silva ( $3^{\mathrm{a}}$ Jornada). Esta sería, por tanto, la obra que Manuela Sánchez Regueira citaba en la edición de las Comedias de Antonio de Solís, pero que no reproducía en ninguno de sus dos gruesos volúmenes ${ }^{29}$.

El orden de la 'representación' es el del manuscrito:

- Loa, de Antonio de Solís. No tiene relación con la comedia. La protagonizan personajes abstractos (Admiración, Envidia, Razón, Juventud, Prudencia, Hermosura).

- Primera Jornada.

- Baile de el contraste de amor, de Juan Vélez.

- Segunda Jornada.

- Baile entremesado de los hombres deslucidos, que se pierden sin saberse cómo ni cómo no, de Jerónimo de Cáncer ${ }^{30}$.

29. F. Serralta me informa de que editó la obra como "'tesis de tercer ciclo' (grado intermedio entre la tesina y la tesis doctoral)", difundiéndose "unos cien ejemplares" y no quedando más que uno en la Biblioteca de la Université de Toulouse Le Mirail. En su monografía (op. cit., p. 59, n. 1) dice textualmente: "Véase mi edición crítica presentada como 'tesis de tercer ciclo' ante la Facultad de Letras de Toulouse, en Junio de 1968. Tirada mecanografiada de muy pocos ejemplares". Además, respecto a la adaptación burlesca dentro de la evolución del tema, el hispanista francés afirmaba en 1970 que: "Las tres jornadas -animada y divertida la de Monteser, entretenida la de Solís, floja e incoherente la de Silva- demuestran sobradamente que los valores primitivos de la historia de la Renegada de Valladolid, agotados por su mismo éxito popular, ya se habían olvidado y sólo quedaban, presentes en todas las memorias, unos episodios conocidísimos pero sin substancia, muy propios de la adaptación burlesca (op. cit., p. 72).

30. Vid. Hannah E. BERGMAN (ed.), Ramillete de entremeses y bailes nuevamente recogido de los antiguos poetas de España. Siglo XVII, Madrid, Castalia, 1984 (2ª ed.), pp. 315-322. 
- Tercera Jornada.

- Entremés de la noche de San Juan y Juan Rana en el Prado con escribano y al [sic] Alguacil, de Jerónimo de Cáncer.

A excepción de este entremés final en el que intervienen hombres y mujeres, esta representación resulta extremadamente inhabitual, puesto que al relacionarse los nombres de los personajes y los nombres de los cómicos correspondientes nos sorprendemos al leer nombres todos de actrices. Once en total. Hannah E. Bergman apunta que, tal vez, serían miembros de varias compañías, pero eso lo dice en su Ramillete de entremeses y bailes, donde incluye el Baile entremesado de los hombres deslucidos que se pierden sin saberse cómo ni cómo no ${ }^{31}$. Sin embargo, hay que tener en cuenta que cuando el manuscrito recoge el reparto que afecta a la comedia todos los representantes son mujeres y algunas, a mayor abundamiento, vestidas de hombre para interpretar los papeles masculinos. Aquí la protagonista recibe el nombre de D. ${ }^{a}$ Agueda de Acevedo, su nombre histórico; en las piezas firmadas por Belmonte es D. ${ }^{a}$ Isabel.

El Ms. 17.192 es el único que aparece fechado y que concreta donde tuvo lugar la representación: "Representóse a su Majestad en el salón del buen Retiro, día de San Juan, año 1655"32.

$2^{\circ}$.- El Ms. 17.447 recoge en el título una variante esencial, puesto que no aparece el término 'renegada': Comedia de la Vida, Conversión y muerte de Agueda de Acebedo, Dama de Valladolid. La comedia pasa de los 5.000 versos y hay en ella muchísimos personajes que intervienen en los diálogos; rondan la treintena y abundan los musulmanes más que en otras obras. Tras el Laus Deo del final de la comedia puede leerse que su autor es Lorenzo de Avellaneda, soldado; la fecha, 1605. El manuscrito incluye, por último, una Glosa sobre la oración del Pater Noster.

$3^{\circ}$.- En el Ms. 17.331 se indica que fue "regalado [a la BN de Madrid, suponemos] por el Sr. D. Sebastián de Mobellán, Conde de Casafiel (?). El título de la obra recogida, La renegada de Valladolid, comedia en tres jornadas, de Luis de Belmonte. Es la reproducida por Mesonero Romanos en el tomo XLV

31. Ibídem, pp. 315-322.

32. Cree F. Serralta que: "Tres días más tarde se repetiría la fiesta, como se acostumbraba en aquella época, para un público menos selecto, en el Coliseo del Buen Retiro [...] Lo que no queda claro hasta ahora es si fue esta representación la primera o si la que tuvo lugar, [...] ante los Señores Condes de Oropesa, fue muy anterior (como lo suponen algunos críticos después de comentar el texto de la loa)" (op. cit., p. 64). Esta comedia es incluida por el Prof. Serralta en la fase religiosa de la trayectoria dramática del tema, junto con otra pieza titulada La cautiva de Valladolid (1598), de Pedro Herrero: "La trayectoria teatral de la Renegada empezó pocos años después de la publicación de las quintillas escritas por Mateo Sánchez de la Cruz. Y empezó, como era de esperar por la profunda religiosidad del tema, con una adaptación destinada a ensalzar la divina bondad de Nuestra Señora del Rosario, y la importancia que tuvo su intercesión para la salvación final de la renegada" (op. cit., p. 25). 
de la B.A.E. y en el Teatro Selecto antiguo y moderno, nacional y extranjero..., de F.J. de Orellana ${ }^{33}$.

$4^{\circ}$.- El Ms. 17.014 titula la comedia también como La renegada de Valladolid y, asimismo, de Luis de Belmonte. Pero aquí, y sobre todo en la Primera Jornada, no se sigue la edición de la B.A.E. El pórtico de la obra es mucho más teatral que el que recoge dicha edición, que empieza con un largo parlamento de $D^{a}$ Isabel. En la Segunda Jornada hay variantes y en la Tercera vemos que hay una total reproducción. Es muy orientativa la lista de personajes que precede al texto dramático, ya que especifica el papel de cada personaje, cosa que no ocurre en los otros manuscritos. Zulema, por ejemplo, se nos presenta como el moro gracioso y Ceylán como el moro galán. En definitiva, nótese el aprovechamiento de este tipo de personajes, no tanto para describir un estado de cosas, sino para reproducir modelos actanciales establecidos de antemano y que adquieren mayor categoría de molde o de patrón en este tipo de obras en que se da una labor conjunta de creación entre varios autores.

$5^{\circ}$.- El Ms. 16.808 contiene la comedia en tres jornadas, de tres ingenios, con el título de La renegada de Valladolid. Al presentar las "Personas que hablan en ella" se dice que es de Luis de Belmonte. El comienzo es el mismo que tiene el Ms. 17.014, aunque el amanuense es distinto. Con diferente letra también comienza la Segunda Jornada que se le atribuye a D. Agustín Moreto, autor de obras tan conocidas de nuestro teatro clásico como El lindo don Diego o El desdén con el desdén, puesta en escena esta última por la Compañía Nacional de Teatro Clásico (C.N.T.C.) hace tres años. La Tercera Jornada, sin embargo, se le atribuye a un tal D. Antonio Martínez de Meneses. Parece otra la letra empleada.

6․- El Ms. 15.325 nos ofrece otra grata sorpresa, el Auto Sacramental del Rosario de la cautiva de Valladolid, nuevo nunca visto. Son figuras la $\mathrm{Fe}$, la Herejía y casi una veintena de personajes más al uso. Con esta pieza el ciclo se cierra ${ }^{34}$. Contamos con las distintas versiones de un mismo asunto argumental, la atribución es individual o colectiva y ahora en este manuscrito se

33. Barcelona, Manero, 1866, t. III, pp. 85-114. Serralta la incluye en la que él llama fase profana de la evolución del tema popular.

34. Como ya hemos expresado en $\mathrm{n}$. 32, Serralta incluyó en la fase religiosa de la trayectoria del tema la pieza de Pedro Herrero titulada La cautiva de Valladolid (1598). Un trabajo posterior más general fue «La religión en la comedia burlesca del siglo XVII», Criticón, 1980, n" 12 , pp. 55-75. Después ha estudiado la octava adaptación teatral conocida hasta hoy en: «Otra adaptación teatral de La renegada de Valladolid», Criticón, n 44, 1988, pp. 135-140. Se trata de un baile, de treinta y cinco versos, basado en el asunto, sin relación con el resto del entremés del que forma parte, titulado Entremés de las fiestas del aldea, de Francisco Bernardo de Quirós, dado a conocer por Celsa Carmen GARCía VAldés en su edición de las Obras de Francisco Bernardo de Quirós y aventuras de don Fruela (Madrid, Instituto de Estudios Madrileños, 1984), y por Javier HuERTa CALvo en su antología de Teatro breve de los siglos XVI y XVII. Entremeses, loas, bailes, jacaras y mojigangas (Madrid, Taurus, 1985). 
produce la culminación, al terminar la serie con la elaboración del auto que acerca el tema al campo de la espiritualidad y del pensamiento filosófico. La letra es la más ilegible de todos los manuscritos citados. No se especifica el autor, aunque sí vemos, además del sello de la B.N. (Biblioteca Nacional de Madrid), el de la Librería del Exmo. [sic] S.D.AG. Durán (?) y se concreta que ésta fue adquirida por el Gobierno en 1863.

Para terminar, sólo añadir la intención de analizar y editar en un futuro este rico material que hoy tan sólo hemos presentado para su divulgación ${ }^{35}$, mostrando interés por atender a un tipo no muy frecuente de conversión religiosa, y, ante todo, proporcionando paradigmáticamente lo que es un elevado tanto por ciento de nuestro teatro clásico, un teatro que mantuvo ilusionado y atento a un público, el del XVII, que, como dijo Vicente Gaos ${ }^{36}$, iba a la comedia a soñar más que a ver.

35. Creo que el tema no es demasiado conocido por parte de los especialistas y, desde luego, casi nada fuera del ámbito de la historia del teatro español del Siglo de Oro. Así pues, pretendo contribuir a la mayor difusión de aquel trabajo primerizo del Prof. Serralta y, desde luego, acepto el reto que me lanza -n carta de 25 de abril de 1995- de emprender juntos, en un futuro próximo, la edición de todos los materiales citados sobre el asunto.

36. «La poética invisible de Lope de Vega», en Claves de literatura española I, Madrid, Guadarrama, 1971, pp. 283-303. 